\title{
AUTOMATED ANALYSIS OF FOAM STABILITY
}

\author{
by
}

\author{
JAN NØRAGER RASMUSSEN
}

Department of Physiology, Carlsberg Laboratory, Gamle Carlsberg Vej 10, DK-2500 Copenhagen Valby

Keywords: Head retention of beer, half-life of foam, electronic measurements, automatic sampling

An apparatus for automated and objective analysis of foam stability has been constructed. It is primarily designed for analysing head retention of beer and measures the half-life of the foam.

The principal component of the design is a $0.6 \mathrm{~mm}$ wide stainless steel nozzle through which a predetermined amount of beer is ejected as foam into a measuring cylinder. The amount of foam formed is measured with a conductivity sensor, which is also used to follow the volume changes occurring as the foam decays.

Foam analysis can be performed at any temperature between 15 and $25^{\circ} \mathrm{C}$ and with amounts of foam ranging between 100 and $200 \mathrm{~g}$. Twenty successive samples can be analysed automatically and the results printed out. The apparatus also contains a cleaning program to be used between analyses.

Tests of various commercial beers with the apparatus have revealed that foam stability is temperature and volume dependent. After a lag of 0.5 to $1 \mathrm{~min}$ the foam decays with time as a logarithmic function of the amount of foam, permitting the determination of its half-life. For a given beer type and within the range of 100 to $200 \mathrm{~g}$ foam its half-life (ht) increases linearly with increasing amounts of foam at time 0 (A). The slope of this increase is a characteristic parameter for the foam of the individual beer type and can be used in an objective characterization of a beer foam.

\section{INTRODUCTION}

Determination of the half-life of foam as a measure of head retention has been introduced by Јаков ВLOM in 1932 (2) and he explored at the Research Laboratory of the Tuborg Breweries the scientific and practical aspects of determining the decay of beer foam. He recognized that head retention is dependent on temperature and on the gas phase with which the foam had been formed, air giving for instance a more stable foam than $\mathrm{CO}_{2}$. Also important is bubble size and the content of $\mathrm{CO}_{2}$ in the beer from which the foam is produced (1). The collapse of the foam consists in a successive shrinkage of the bubbles and a flowing out of the beer from the foam into the liquid concurrent with the diffusion of the gas into the air. After an initial lag of about 30 seconds the conversion of foam 
into beer follows a first order process, which permits to evaluate the quality of head retention for a given type of beer by determining the half- life of its foam. For the basis of comparison a constant amount of foam is used.

To measure the half-life time of foam BLOM

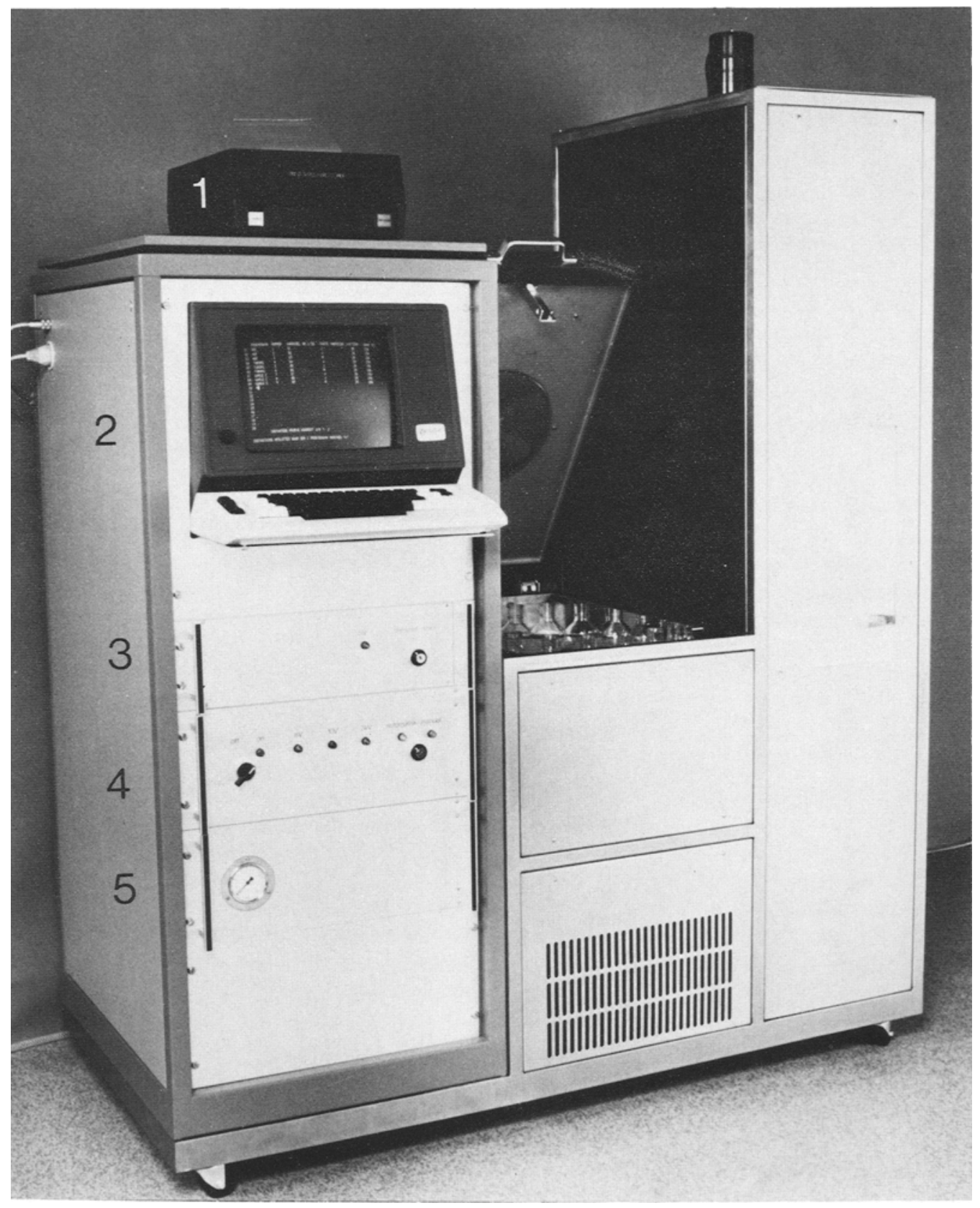

Figure 1. Apparatus for automated measurement of foam stability.

1) Printer, 2) Display unit with keyboard, 3) Microcomputer, 4) Power supply and 4 test points from sensors, 5) Solenoid valves, pressure regulators and safety valves. 
constructed an apparatus, the decisive component of which is a ceramic filter, called a Chamberland candle. The rod shaped $6.5 \mathrm{~cm}$ long filter is placed at the end of a tube connected to a $\mathrm{CO}_{2}$ pressure tank and inserted into the measuring cylinder containing $200 \mathrm{~g}$ beer. The beer is converted into foam by ejecting $\mathrm{CO}_{2}$ through the ceramic filter. The foam is weighed and re-weighed at intervals of one minute over a 4 minute period as the foam diminishes.

The half-life of the foam is sensitive to the size and number of the pores in the ceramic filter and these are difficult to manufacture reproducibly. In the present apparatus the ceramic pore filter has therefore been replaced by a stainless steel nozzle of $0.6 \mathrm{~mm}$ diameter which can be machined with great precision.

A large number of samples is to be analysed in the control laboratories of breweries producing different types of beer at many different localities. In order to avoid the constant attention required by the person carrying out the analyses and to increase the number of samples which can be analysed per day, an apparatus has been constructed which allows the fully automated analysis of 20 successive beer samples and calculates as well as prints out the half-life of the foam for each sample. The measuring principle is no longer based on weighing the foam but on the volume changes of the beer and the collapsing foam.

\section{DESCRIPTION OF THE APPARATUS}

As shown in Figure 1 the apparatus for automated electronic measurement of head retention of beer consists of a temperature controlled stainless steel cabinet housing the foam analyzer and an electronic unit (at left).

The electronic unit comprises from top to bottom 1) printer, 2) display unit with keyboard, 3) microcomputer, 4) power supply and 4 test points from sensors, 5) solenoid valves, pressure regulators and safety valves. The stainless steel cabinet houses in its low section a refrigerating unit providing a constant temperature of $8{ }^{\circ} \mathrm{C}$. Above the refrigerator is located the turntable containing the 20 beer samples for analysis in glass or stainless steel bottles. The beer is filled into the bottles and removed after analysis by lifting the cover of the middle section

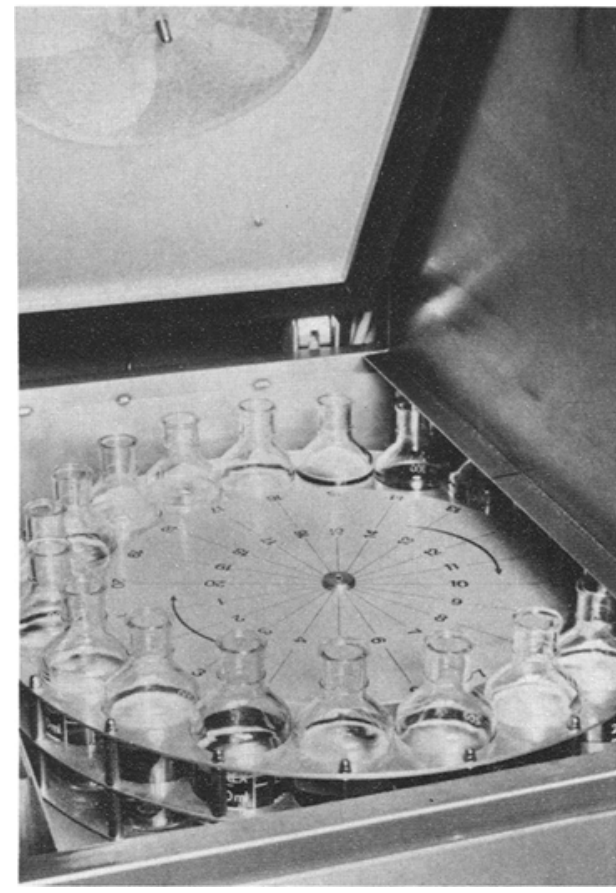

Figure 2. Turntable with bottles for the beer to be sampled.

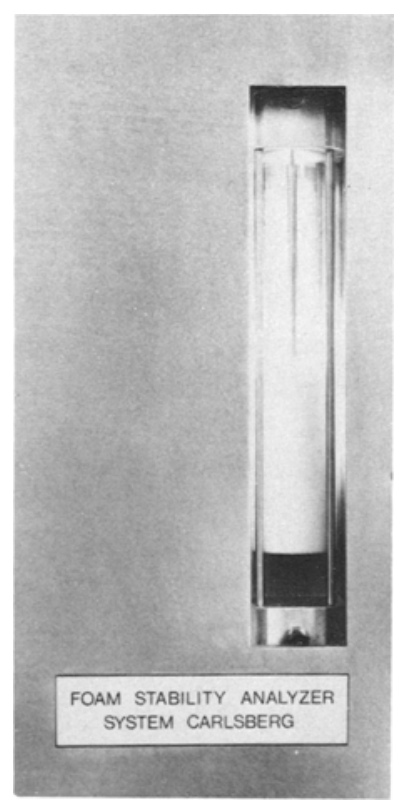

Figure 3. Measuring cylinder with conductivity sensor, which follows the foam-beer interphase. 

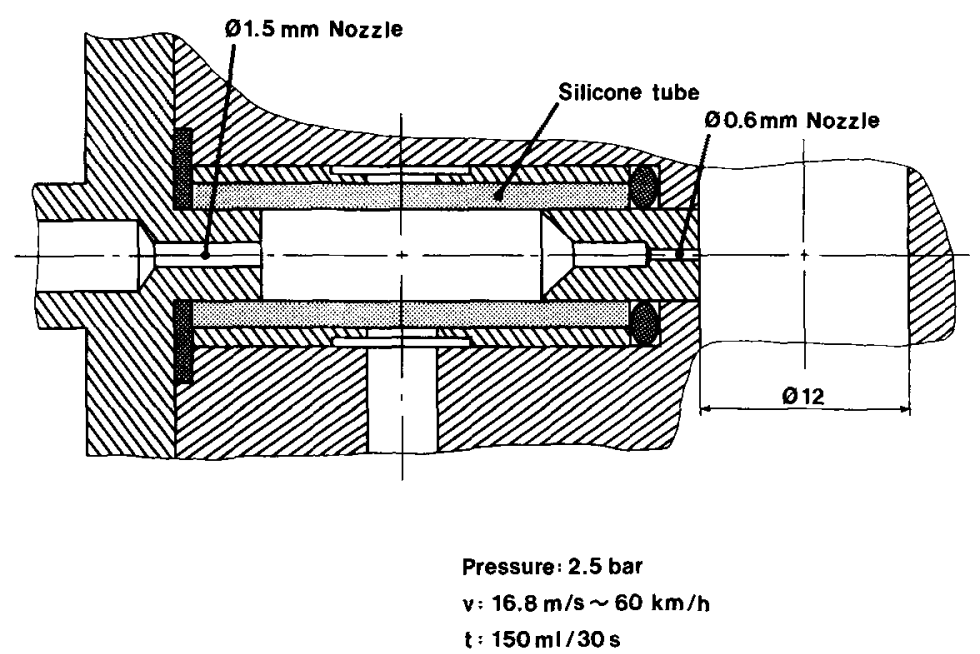

Figure 4. Diagram of the serially placed stainless steel nozzles through which the beer is ejected to form the foam in the measuring cylinder.

(Figure 2). The high section of the stainless steel cabinet houses at the bottom a heating element and above it a cooling unit. It houses further the measuring cylinder (Figure 3), the sampler and the three reservoirs for waste and rinsing fluid. In the rear wall is placed a switch-board which upon activation from a changeover in the electronic unit permits manual operation af all mechanical functions.

The temperature inside the cabinet is held constant with an accuracy of $0.2^{\circ} \mathrm{C}$ and can be set at any value between 15 and $25^{\circ} \mathrm{C}$. Temperature control is achieved by two fans mounted in the roofs of the middle and high sections of the cabinet. The fans blow air through ducts in the side walls to pass over the heating and cooling elements in the bottom of the cabinet. Between the elements and the measuring cylinder is placed a Pt $100 \Omega$ temperature sensor which is read every 16th second by the microcomputer. The signal is used to regulate the heating element.

The most important task of the apparatus is the reproducable production of foam. This is achieved by ejecting the beer with a pressure of 2,5 bar $\mathrm{CO}_{2}$ through two serially placed stainless steel nozzles, the first with a diameter of $1.5 \mathrm{~mm}$ and the second with a diameter of $0.6 \mathrm{~mm}$ (Figure 4). The two nozzles are mounted at the two ends of a silicone tubing which functions as valve: After formation of the foam the tubing is compressed with a pressure of 8 bar preventing the foam and beer liquid to flow back through the nozzle. The beer passes the second nozzle with a speed of $16.8 \mathrm{~m} / \mathrm{s}$ and moves as foam through a $12 \mathrm{~mm}$ opening into the measuring cylinder.

As the density of beer is about 1 the measuring principle is based on determining the increase in the volume of liquid beer per unit time: As the foam is transformed into liquid beer, a conductivity sensor automatically follows the foam-liquid interphase and moves upward with the interphase as the liquid beer forms. The sensor is mechanically coupled to a slide resistor which is read by the microcomputer every 10 th second (Figure 5).

The measuring gauge is a glass cylinder with a diameter of $52 \mathrm{~mm}$, whereby $1 \mathrm{~mm}$ height difference of beer corresponds to a difference of $2.12 \mathrm{~g}$. The aluminium top and bottom of the measuring cylinder is conically shaped to facilitate automatic rinsing between measurements.

The samplers task is to remove an exact amount of beer from the bottle on the turntable and eject it through the nozzles. The sampler consists of a stainless steel tube with an inner diameter of $6 \mathrm{~mm}$ and a Pt $100 \Omega$ temperature sensor both of which are moved vertically by a pneumatic cylinder. The position is determined 
J. N. RasmusSEN: Automated analysis of foam

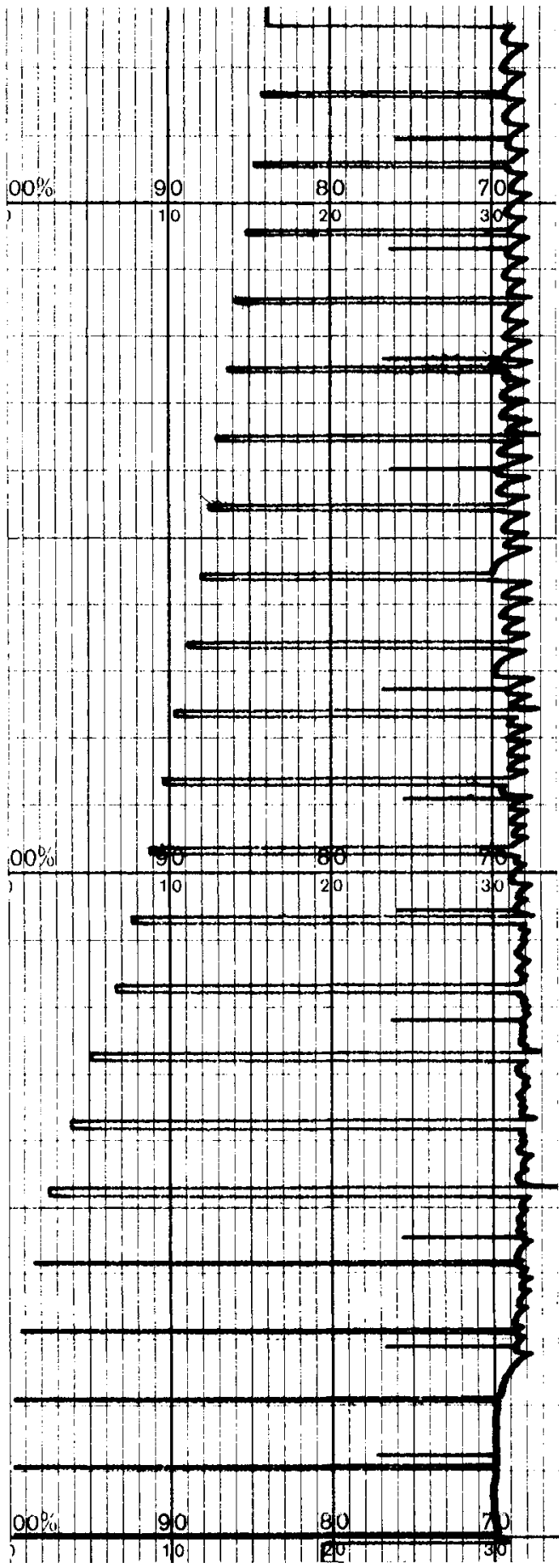

Figure 5. Recording of the signals received by the computer over one measuring cycle of 4 minutes.

The large successively diminishing spikes show the position of the height of the resistor moved by the conductivity sensor. The waves of the baseline record the movement of the conductivity sensor at the foam beer interphase. The small spikes between the large ones are signals from the temperature sensor. with a coupled slide resistor. The tube and sensor are electrically insulated from each other and can thus be used as a conductivity sensor. The 250 $\mathrm{ml}$ bottles for the beer samples are of glass or stainless steel with a cover for automated opening to avoid escape of $\mathrm{CO}_{2}$ while the beer is waiting to be sampled. The diameter of the bottles is $60 \mathrm{~mm}$ and has to be constant within $0.1 \mathrm{~mm}$. For removal of a precise amount of beer the sampling tube is attached to a bottle. whereafter the tube and temperature sensor (which together constitute a conductivity sensor) are moved into the bottle until they reach the surface of the beer. The conductivity change experienced by the sensor is signalled to the microcomputer which then reads the value of the slide resistor and calculates the amount of downward movement of the sampling tube required to dispense the desired amount of beer. If this is not feasible, e.g. because of insufficient amounts of beer in the bottle, the sampler is withdrawn from the bottle and goes to the next bottle after movement of the turntable. When the tip of the sampling tube has reached a level of $10 \mathrm{~mm}$ below the surface of the beer the absolute conductivity is measured and used to establish the measuring range of the conductivity sensors in the sampler and in the measuring cylinder.

In the following is given a description of the functions in chronological order as carried out by the apparatus in the course of a foam stability analysis. A diagram to aid the description is provided in Figure 6. The beer samples are placed in the bottles of the turntable and information about the samples is fed into the microcomputer using the key-board. The apparatus starts by filling de-ionized water into a tank followed by an order for the sampler to attach to the first sample. In the meantime a small reservoir bottle is filled with water to be used for rinsing tubing and nozzles after the measurement is completed. When the sampler tube has reached the beer surface and the microcomputer has determined the level at which the tube opening is to be set (as described above), the tube is placed at the proper level and the computer waits $15 \mathrm{sec}$ before determining the samples temperature. If the temperature is within $\pm 0.5^{\circ} \mathrm{C}$ of the desired one the sample is accepted, otherwise the test is repeated at intervals of 5 seconds until the temperature is 


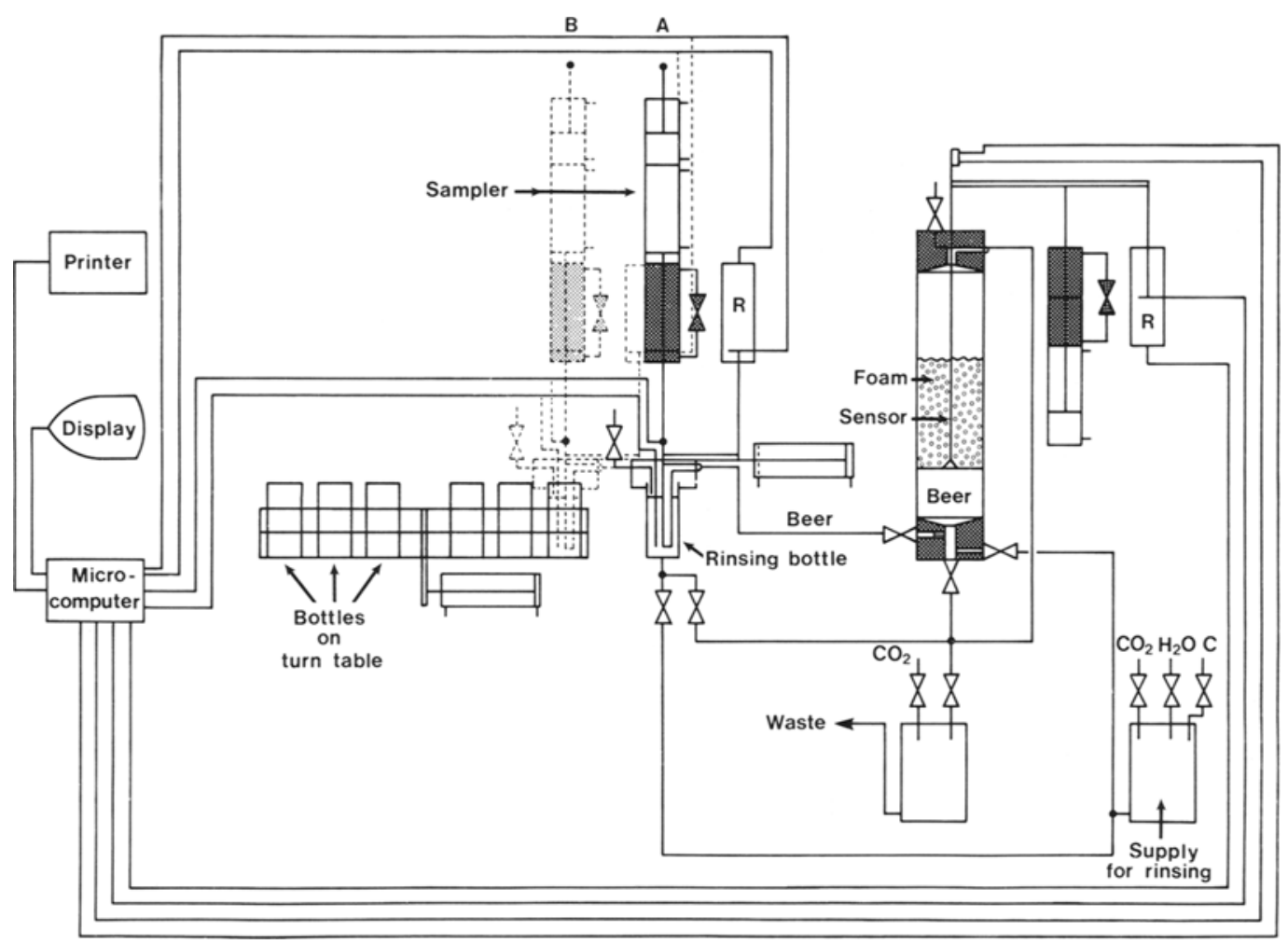

Figure 6. Diagram of apparatus for automated measurement of foam stability.

$\mathrm{C}=$ Cleansing solution; $\mathrm{R}=$ slide resistor, $\mathrm{A}$ : Rinsing position, B: Sampling position.

correct. Next the measuring cylinder is rinsed twice with water, unless an earlier measurement has taken place within the previous 6 minutes. This function insures that the cylinder always has the same humidity prior to production of the foam. After the computer has registered that all water has left the cylinder its conductivity sensor rides to the top and foaming starts by applying a $\mathrm{CO}_{2}$ pressure of 2.5 bar. When the conductivity sensor of the sampler has registered that the bottle has been emptied appropriately, some additional seconds are allowed for emptying the tubings. The tube valve between the two nozzles is closed and measurement of head retention over a duration of 4 minutes starts. The conductivity sensor in the measuring cylinder moves slowly downward until it reaches the foam surface and from its level the foam volume is calculated by the microcomputer. After this measurement the conductivity sensor moves rapidly to the bottom of the cylinder and waits for the first liquid beer to form from the foam. Thereafter the sensor follows the foam-beer interphase and the microcomputer reads every 10 th second the value of the slide resistor as an indicator for the amount of beer liquid which has formed. After the 4 minutes have elapsed the beer and foam is emptied into the waste tank. The sampler is moved and coupled to the small water reservoir bottle filled at the beginning of the measurement. With $\mathrm{CO}_{2}$ pressure the rinsing water is sent - quite analogous to sample taking - through the tubing and the nozzles after opening of the valve. Subsequent to rinsing of the sampler, tubing and nozzles the measuring cylinder is flushed twice under pressure with water from the large water tank. When the computer has registered that all rinsing fluid has left the system, the turntable moves the next sample into operating position and the measure- 

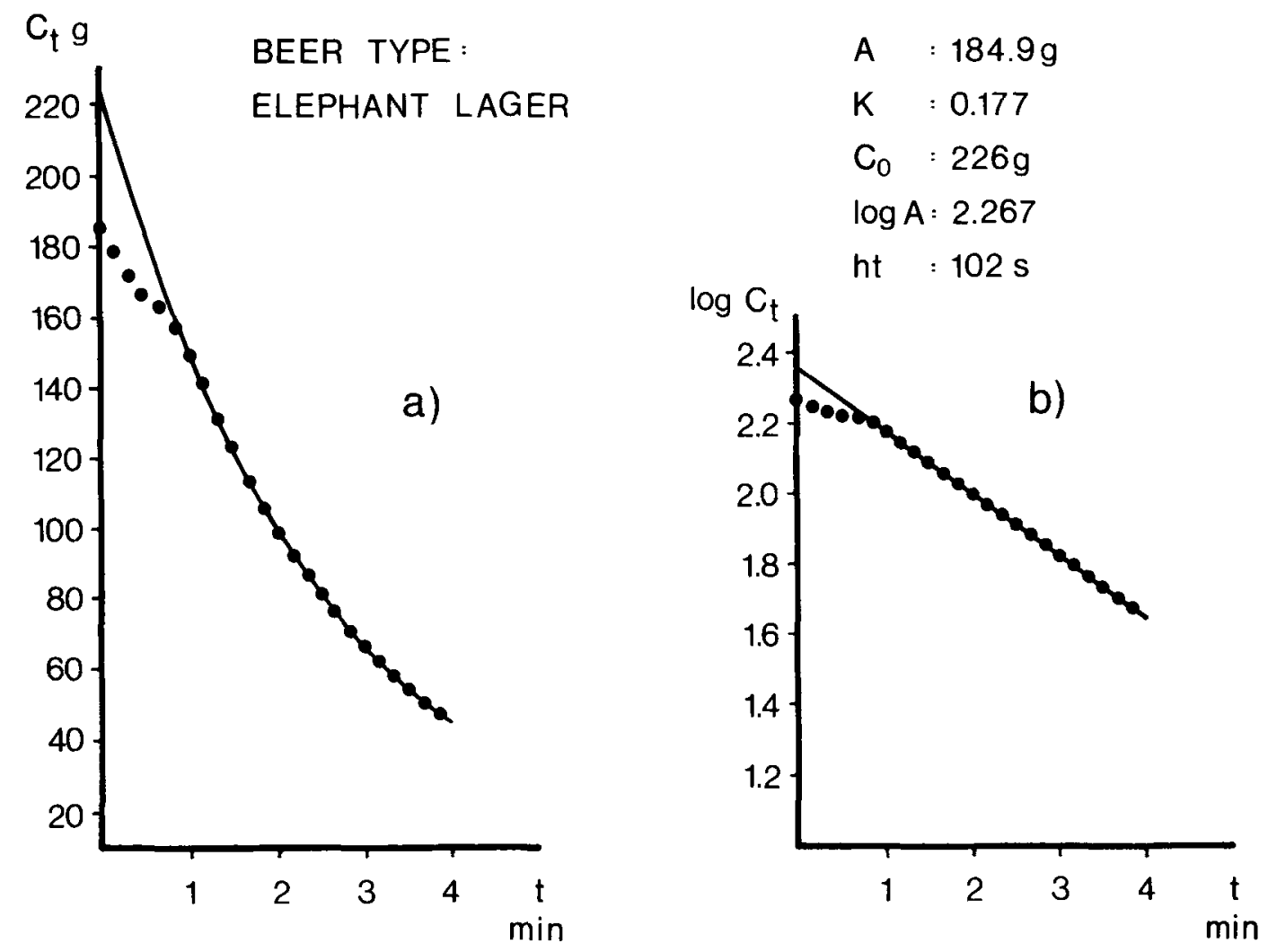

Figure 7. Plots of amount of foam remaining versus time.

a) amount in $g$; b) log of amount.

ment procedure is repeated. The 20 cycles of measurement and rinsing will be completed in 2.5 hours.

Every signal given by the microcomputer for performance of a function elicits supervision for a given number of seconds. If the function is not carried out the type of error is registered on the display board as well as printer and measurements are not continued until the fault has been corrected. Excepting the three fans and one compressor, all mechanical movements are pneumatic. For highest possible precision the conductivity sensors are moved hydropneumatically. The pressure for the mechanical movements and foaming is provided by a commercial $\mathrm{CO}_{2}$ pressure tank. The functions described are operated with 57 valves comprising 25 solenoid valves, 14 machanically controlled valves, 10 one-way restrictors, 5 check valves, 2 pressure regulators and 1 safety valve.
Additionally are used 7 pneumatic cylinders and 2 rotary cylinders. For control of the functions are installed besides the $2 \mathrm{Pt} 100 \Omega$ temperature sensors, the 2 conductivity sensors, the 2 slide resistors, 16 inductive sensors, 7 capacitors and 1 pressure switch, amounting to 30 controlling devices. The microcomputer from $\mathrm{H}$. H. Electronics, Fredensborg, Denmark is an 8 bit microprocessor with direct adressing for up to 64000 bytes and with direct adressing of up to 256 input-output gates. Presently, the apparatus uses 8000 bytes for the program and 60 input-output gates.

\section{DETERMINATION OF A FOAMS HALF-LIFE}

In BLom's (2) technique for measuring foam stability the half-life of a given amount of foam is determined and this value is used by the 
Carlsberg and Tuborg Breweries to evaluate the quality of head retention. Using $100 \mathrm{~g}$ foam produced by foaming of $200 \mathrm{~g}$ beer and discarding half of the volume, a good head retention is recognized by a half-life of more than 90 seconds and a poor head retention by a halflife of less than 75 seconds. In the present apparatus no adjustment of the amount of foam after its formation is required.

The primary measurement consists in determining the amount of beer formed from the foam at frequent intervals over a four minute period. The computer has determined the amount of foam originally present (A) in the measuring cylinder at time 0 and subtracts from this value the amount of beer formed at the time of measurement. This allows to plot the amount of foam in $\mathrm{g}$ present at various times over the four minute period (Figure 7).

As can be seen in Figure $7 \mathrm{a}$ that the foam decays with time as a logarithmic function of the amount of foam, but only after an initial lag of 0.5 to 1.0 minute. If the logarithm of the amount of foam remaining is plotted against time (Figure 7b) a straight line is obtained for values after the one minute lag. By regression analysis the velocity constant $\mathrm{k}$ is calculated from the slope of the line. The line intercepts the $y$-axis at a value corresponding to the logarithm of the amount of foam expected if the decay of the foam had followed the same function from time 0 . The intercept is designated as $\log \mathrm{C}_{0}$. It was already known to BLom (2) that the decay during the first minute is slower than expected and does not follow the process that governs the disappearance of the foam after one minute, which is given by the formula $\mathrm{k}=\left(\log \mathrm{C}_{0}-\log \mathrm{C}_{\mathrm{J}}\right) / \mathrm{t}$, when $\mathrm{k}$ is the velocity constant at time $\mathrm{t}, \mathrm{C}_{0}$ the amount of foam extrapolated to time 0 and $C_{t}$ the amount of foam remaining at time t. The half-life (ht) is given by the formula $h t=18.06 / k$.

If for a given type of beer, i.e. a given type of foam the half-life (ht) is plotted against the foam present at time 0 (A) a straight line is obtained in the range of 100 to $200 \mathrm{~g}$ foam (Figure 8). This is the range for which the apparatus is built and which is of practical importance for the brewer. The relationship is defined by the equation $\mathrm{ht}=$ $60.67+0.43$ (A-100). As will be shown in section 4 of this paper the equation is similar for most of the analysed types of beers but clearly different for the foam of Carlsberg "Porter«. The apparatus permits, however, for any type of foam a precise and easy determination of the relationship between the amount of foam present at time 0 (A) and the half-life (ht).

The apparatus can be used in two modes: (1) If it is desired to perform the classical BLom analysis, the half-life of $180 \mathrm{~g}$ foam can be determined and recorded. (2) An objective measure of the foam quality can be provided by specifying the desired relationship between amount of foam and its half-life. It can then be tested whether a given foam conforms to this relationship. The microcomputer can be programmed to perform the test.

\section{MEASUREMENTS OF HEAD RETENTION FOR VARIOUS TYPES OF BEER}

Performance of the apparatus is illustrated by determination of the half-life of the foam for 20 bottles of commercially produced Tuborg lager beer ( $) g r ø n «)$. The data are presented in Table I comprising the temperature in the beer at the time of sampling, the amount of foam produced at time 0 (A) in $\mathrm{g}$ and $\mathrm{ml}$, the amount of foam extrapolated to time $0\left(\mathrm{C}_{0}\right)$, the velocity constant $\mathrm{k}$ and the half-life of foam (ht). Also included is the half-life for $180 \mathrm{~g}$ foam $\left(\mathrm{ht}_{180}\right)$ calculated with the equation established in the experiment of Figure 8. This corresponds to BLom's number as used today in the breweries. The apparatus was programmed to measure at $20^{\circ} \mathrm{C}$ and to sample $155 \mathrm{~g}$ beer. The recorded temperature

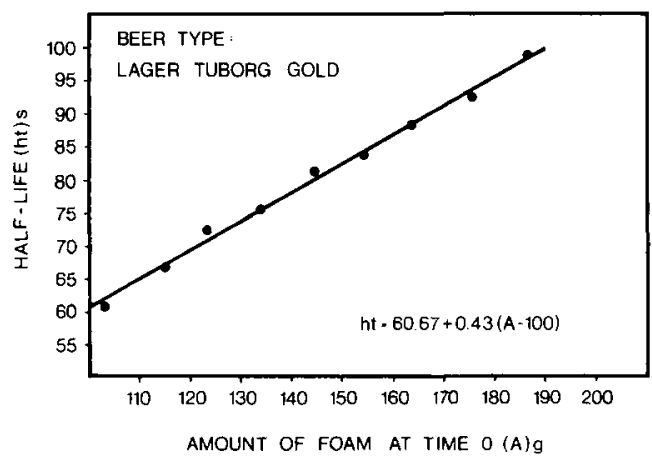

Figure 8. Plot of foam half-life in seconds versus amount of foam in measuring cylinder in $\mathrm{g}$ (A). 
Table I

Determination of the half-life of foam for 20 bottles of Tuborg lager beer ("gron»).

\begin{tabular}{|c|c|c|c|c|c|c|c|}
\hline 䒿 & 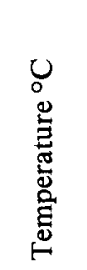 & 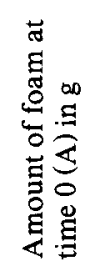 & 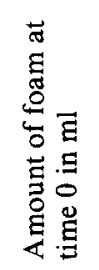 & 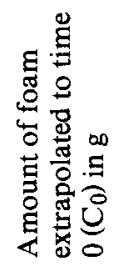 & 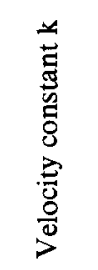 & 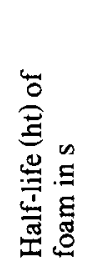 & 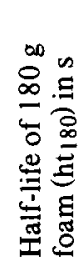 \\
\hline 1 & 19.5 & 154.9 & 344.0 & 171 & 0.221 & 82 & 93 \\
\hline 2 & 20.1 & 155.1 & 341.9 & 170 & 0.229 & 79 & 90 \\
\hline 3 & 20.2 & 156.5 & 338.8 & 165 & 0.230 & 78 & 88 \\
\hline 4 & 19.9 & 155.4 & 359.0 & 184 & 0.228 & 79 & 90 \\
\hline 5 & 20.2 & 156.1 & 346.0 & 173 & 0.219 & 82 & 92 \\
\hline 6 & 20.3 & 155.2 & 336.8 & 163 & 0.230 & 78 & 89 \\
\hline 7 & 19.9 & 154.8 & 363.1 & 185 & 0.223 & 81 & 92 \\
\hline 8 & 20.1 & 155.1 & 349.7 & 179 & 0.230 & 78 & 89 \\
\hline 9 & 20.3 & 155.2 & 344.0 & 166 & 0.226 & 80 & 91 \\
\hline 10 & 20.0 & 154.7 & 336.2 & 164 & 0.226 & 80 & 91 \\
\hline 11 & 20.2 & 154.8 & 350.7 & 177 & 0.223 & 81 & 92 \\
\hline 12 & 20.3 & 155.0 & 343.4 & 172 & 0.223 & 81 & 92 \\
\hline 13 & 20.1 & 154.1 & 353.8 & 180 & 0.228 & 79 & 90 \\
\hline 14 & 20.2 & 155.6 & 344.0 & 171 & 0.232 & 78 & 89 \\
\hline 15 & 20.3 & 156.1 & 323.3 & 153 & 0.216 & 84 & 94 \\
\hline 17 & 20.3 & 155.2 & 344.5 & 170 & 0.233 & 77 & 88 \\
\hline 18 & 20.3 & 155.1 & 336.2 & 164 & 0.226 & 80 & 91 \\
\hline 19 & 20.1 & 155.8 & 348.6 & 175 & 0.222 & 81 & 92 \\
\hline 20 & 20.1 & 153.6 & 348.1 & 178 & 0.220 & 82 & 93 \\
\hline
\end{tabular}

varied between $19.5^{\circ} \mathrm{C}$ and $20.3^{\circ} \mathrm{C}$ and the recorded amount of foam in the measuring cylinder between 153.1 and $156.5 \mathrm{~g}$ giving a volume ranging from 323.3 to $363.1 \mathrm{ml}$. From the velocity constant the half-life of the foam was determined and varied between 77 and 84 seconds. If the half-life for $180 \mathrm{~g}$ foam was calculated the variation was found to lie between 88 and 94 seconds.

Figure 9 has been prepared to show for seven types of commercially produced beer the influence of temperature and foam amount on the 

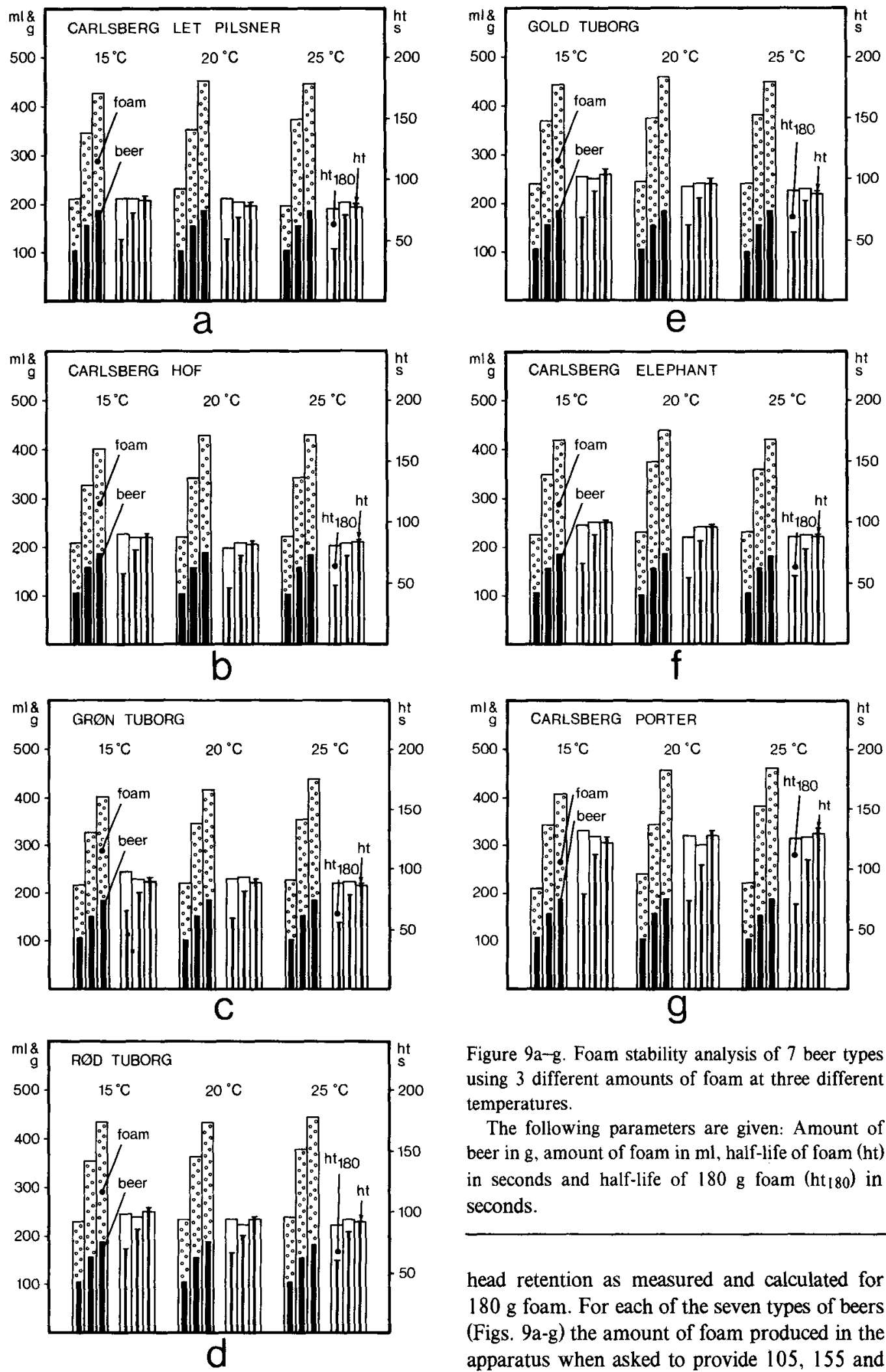

Figure $9 \mathrm{a}-\mathrm{g}$. Foam stability analysis of 7 beer types using 3 different amounts of foam at three different temperatures.

The following parameters are given: Amount of beer in $\mathrm{g}$, amount of foam in $\mathrm{ml}$, half-life of foam (ht) in seconds and half-life of $180 \mathrm{~g}$ foam $\left(\mathrm{ht}_{180}\right)$ in seconds.

head retention as measured and calculated for $180 \mathrm{~g}$ foam. For each of the seven types of beers (Figs. 9a-g) the amount of foam produced in the apparatus when asked to provide 105, 155 and 
$185 \mathrm{~g}$ of foam in the measuring cylinder is presented as black columns for three different temperatures. The black columns are inscribed in white columns representing the measured volumes of the foam. The volume of foam produced by a given amount of beer can vary with the type. For instance Carlsberg »Let Pilsner« (Figure 9a) produced at all three temperatures a slightly more voluminous foam than Carlsberg »Hof « (Figure 9b). While there is a consistent increase in the volume of the foam as the temperature is raised from $15^{\circ}$ to $20^{\circ} \mathrm{C}$ frequently no further increase, if not a reduction of foam volume was observed, when measurement was done at $25^{\circ} \mathrm{C}$ rather than $20^{\circ} \mathrm{C}$.

Foam stability is given in the right part of each set of histograms: The bars indicate the measured half-life times. In all instances the halflife increased with the increasing amount of foam tested. The slope of the increase in half-life was very similar with all beer types except for Carlsberg »Porter« (Fig. 9g) which displays a significantly steeper slope. Using the function that defines the relation between the amount of foam and its half-life, the half-life for $180 \mathrm{~g}$ foam $\left(\mathrm{ht}{ }_{180}\right)$ was determined for each sample. Very good agreement is obtained for each set of three values determined from the widely differing amounts $(105,155$ and $185 \mathrm{~g})$. With the exception of Carlsberg "Porter «, the foam of all types of beer showed a longer half-life at $15^{\circ} \mathrm{C}$ than at 20 and $25^{\circ} \mathrm{C}$. The $180 \mathrm{~g}$ foam of "Porter" had a half-life around 130 seconds compared to the 80 to 100 seconds characteristic for the other beer types.

\section{ACKNOWLEDGEMENTS}

I am grateful to Professor D. von WetTSTEIN for initiating this project and encouragement. Central Laboratory Manager IB Rosendal and J. A. Sørensen, Department of Brewing Chemistry have been most helpful with advice and information on analyses of head retention. Cand. stat. LisBeth SEJERSEN, Carlsberg Research Centre is thanked for help with the calculations and Ms. Nina Rasmussen and Ms. AnN-Sofl StEINHOltz for graphic work.

\section{REFERENCES}

1. Ault, R. G., E. J. Hudson, D. J. Linehan \& J. D. WoODWARD: A practical approach to the assessment of head retention of bottled beers. J. Inst. Brew. 73, 558-566 (1967)

2. Bıом, J.: Über die Bestimmung der Haltbarkeit des Schaumes. Europ. Brewery Conv. Congr. Proc. Copenhagen 1957, p. 51-56 (1957)

\section{APPENDIX: \\ DESCRIPTION OF THE ANALYTICAL METHOD}

The beer is poured into the $250 \mathrm{ml}$ bottles with an accurate diameter of $60 \pm 0.1 \mathrm{~mm}$ after it has been pre-cooled to $0^{\circ} \mathrm{C}$ to avoid foaming and excessive loss of $\mathrm{CO}_{2}$. The bottles are then placed in the desired order on the turntable (Figure 2) and the cover of the cabinet is closed.

The apparatus is started by turning the switch on the power supply (Figure 1) after insurance that the $\mathrm{CO}_{2}$ tank is joined to the machine, has a pressure of 8 bar and that deionized water is available. An optical alarm signal appears on the display screen, if these conditions are not fulfilled. On the screen the question is displayed if one wishes to operate the cleaning program or an analytical program. Upon election of the analytical program on the key-board, the screen displays a scheme into which the following information is keyed: name of beer, sample number and place on turntable. The screen now poses the question if the user would like to operate in the fixed mode or in the variable mode. The fixed mode is set at $180 \mathrm{~g}$ foam and $20^{\circ} \mathrm{C}$, whereas the variable mode permits selection over the entire range from 100 to $200 \mathrm{~g}$ foam and from 15 to $25^{\circ} \mathrm{C}$. Different amounts of foam or different temperatures can be analysed in successive samples on the turntable. A further option is the print-out of the individual measurements of foam in $\mathrm{g}$ remaining every 10 th second over the 4 minute analysis period.

The user programs the computer by either operating the key for the fixed mode or by keying in the 20 different analyses to be performed, whereafter a star $\left(^{*}\right)$ is keyed in and the analysis starts. Each analysis takes about 7.5 minutes including the 4 minutes during which the decay of the foam is measured. When the program has advanced to the temperature 
measurement of the sample, the screen displays the chosen and the measured value. The foaming will first occur, when both values are the same indicating that the sample has acquired the desired temperature.

After completion of each analysis the following information is printed out as exemplified by an analysis from Table I.

NAME: Tuborg lager beer

Analysis No. 200

Turntable No.:

INITIAL AMOUNT (A):

FOAM VOLUME:

TEMPERATURE:

INTERCEPT:

$\mathrm{C}_{0}$ :

VELOCITY CONSTANT (k):

HALF-LIFE (ht):
When all samples have been analysed, the program returns to the start and the initial question is again displayed: cleaning program or analytical program. At the back of the high part of the apparatus is a connection for supplying cleansing solution, which permits the apparatus to be cleaned by selecting the cleaning program which then is operated. It ends the same way as the analytical program and the apparatus is ready for the next set of analyses.

The computer is programmed to probe the $\mathrm{CO}_{2}$ pressure on the tank connection prior to each analysis insuring that there is always enough $\mathrm{CO}_{2}$ to run the next sample to completion. If the pressure is insufficient a display signal appears stating: main pressure not $\mathrm{OK}$. The program is interrupted until a shift of the pressure tank has taken place, whereafter the analysis program continues. 